\title{
Phenylketonuria presenting an intermittent progressive course
}

\author{
M. BECHAR, B. BORNSTEIN, M. ELIAN, AND U. SANDBANK
}

From the Department of Neurology and the Laboratory of Neuropathology, Department of Pathology, Beilinson Hospital, Petah Tiqva, Israel

Phenylketonuria as well as the whole group of inborn errors of metabolism has attracted increasing interest lately. The use of new, refined tests (Guthrie and Susi, 1963) has made possible the early diagnosis of the disease and hence suitable treatment with favourable results (Hudson, Dickinson, and Ireland, 1963). The anatomical and pathological changes in the central nervous system are as yet ill-defined and additional cases may contribute to the further understanding of the pathogenesis of the disease.

It is not yet known whether the changes in the central nervous system begin in the prenatal or postnatal period. Nor do we know whether the condition is a progressive one, or whether the clinical manifestations are the results of one, single irreversible lesion.

The predominant clinical signs are mental retardation of various degrees accompanied by neurological manifestations of trembling, restlessness, convulsive attacks, and paresis. These symptoms are accompanied by typical biochemical findings in the blood, urine, and cerebrospinal fluid, all of which are related to the disturbed metabolism of phenylalanine. Although mental retardation is the cardinal symptom, several authors have reported a minimum, or even complete absence, of mental changes (Woolf, Ounsted, Lee, Humphrey, Cheshire, and Steed, 1961 ; Caudle, 1960; Sutherland, Berry, and Shirkey, 1960). The disease generally manifests itself in early infancy and once the symptoms have been established there is no regression. The following case showed atypical intermittent progressive evolution with general pathological lesions of the central nervous system differing somewhat from those in the cases reported in the relevant literature.

\section{CASE REPORT}

A 23-year-old woman, single, was born in Yemen. The history of her early years, as well as that of her family, is difficult to obtain. Three siblings died in Yemen at a young age; no clinical history is available. The cause of the father's death is also unknown. Her elder sister and mother are healthy. From what her sister reports, it would seem that the patient had been mentally retarded from early childhood. She arrived in Israel at the age of 10. Although she was sent to school for one year, she could not read or write, and was unable to perform elementary mathematical problems. She even failed to learn the language, in spite of the fact that people from Yemen usually do so very easily. She was quiet and very dependent, doing only the simplest work at home. Her condition remained the same up to the age of 22 years. At the age of 22 her family noticed a sudden deterioration in her state. Her slow speech became sluggish and unintelligible. Sudden states of excitement appeared, accompanied by disturbance of orientation. She complained of difficulty in walking and of a feeling of heaviness in her legs. In the following months extreme weakness of the lower extremities developed. She was unable to stand or walk without support. Because of the continued deterioration she was admitted to hospital.

On admission, she gave the impression of being older than her stated age. Her height was $147 \mathrm{~cm}$. and her weight $37 \mathrm{~kg}$. She had fair hair, which contrasted with the dark hair of her mother and sister. The complexion of her skin was also fair, as contrasted with that of her family and ethnic group. Her eyes were blue. She showed slight prognathia.

Physical examination showed no remarkable findings. Blood pressure showed hypertension in the range of $160 / 100$ to $190 / 120 \mathrm{~mm}$. Hg. A marked increase in the tone of all extremities was observed, as well as hyperreflexia with clonus of both hands with bilateral pyramidal signs. She was unable to stand or walk. The patient was completely uncooperative, so that no definite conclusions as to her sensory defects could be reached. The impression, however, was that no sensory defects existed. Her speech was sluggish and dysarthic. The control of the sphincters was normal. The patient was lying in bed completely disinterested in her surroundings. She answered simple questions with short, poor sentences.

PSYCHOLOGICAL EXAMINATION (Mrs. Ruth Gil) According to the Terman-Binet test, her mental age was 3 years and 11 months, and her I.Q. below 30. Visual perception was according to the age of $2 \frac{1}{2}$ years. Concentration level equalled age 3 years, and thinking level approximately $4 \frac{1}{2}$ years. The Vineland social maturity test was based on details given by her sister, and showed that her social age 
was 2-3 years, and, according to her sister, it had deteriorated severely lately. Several months previously the patient had been at an 11-year-old age level.

BIOCHEMICAL EXAMINATION The diagnosis of phenylketonuria was based on the following tests:-

Phenylalanine In urine, $53 \mathrm{mg} . / 24 \mathrm{hr}$.; in blood, $30 \mathrm{mg} . / 100 \mathrm{ml}$.; in cerebrospinal fluid, $6.1 \mathrm{mg} . / 100 \mathrm{ml}$. The urine was examined by the following tests: ferric chloride test, phenylpyruvic acid, once positive and twice negative; dinitrophenyl hydrazine test, slightly positive; chromatographic examination, small quantity of phenylpyruvic acid, orthohydroxyphenylacetic acid; $40 \mu \mathrm{g} . / \mathrm{mg}$. creatinine; Indican $0.083 \mu \mathrm{g} . / \mathrm{mg}$. creatinine (normal 0.04-0.14); quantitative test of urine for indollactic acid and indolacetic acid gave $14 \mu \mathrm{g} . / \mathrm{mg}$. creatinine (normal, 4-15 $\mu \mathrm{g} . / \mathrm{mg}$. creatinine).

On many occasions the blood urea level was between 108 and $178 \mathrm{mg}$. $/ 100 \mathrm{ml}$. Endogenous creatinine clearance was $7.4 \mathrm{ml} . / \mathrm{min}$. and urea clearance $14 \%$; uric acid $7.3 \mathrm{mg} . / 100 \mathrm{ml}$. The 24 -hour protein excretion varied between 2.4 and $2.8 \mathrm{~g}$. The sediment showed many leucocytes and some erythrocytes. Repeated urine cultures were positive for $E$. coli with a count above 100,000 per $\mathrm{ml}$. On a $2 \mathrm{~g}$./day salt diet the $24 \mathrm{hr}$. urinary electrolytes were: sodium $76 \mathrm{mEq}$., chloride $72 \mathrm{mEq}$., calcium 44 mg., and phosphorus $68 \mathrm{mg}$. In the dilution test of urine, specific gravity was 1005 while after dehydration the maximal achieved specific gravity was 1009; the output of urine was never above $345 \mathrm{ml}$./per $24 \mathrm{hr}$. The haemoglobin was $8.5 \mathrm{~g} . / 100 \mathrm{ml}$. with $2,500,000$ erythrocytes /c. mm. Liver function tests, serum electrolytes, total protein, and blood sugar were in the normal range.

Radiographs of the skull and thorax were unremark-

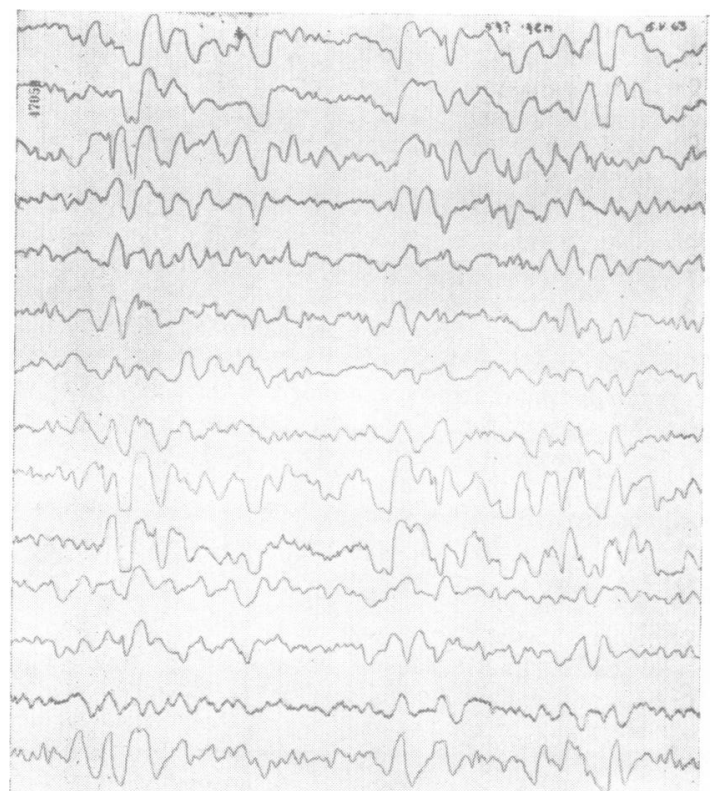

FIG. 1. E.E.G. of the patient. able. Tomography of the kidneys showed them to be small. The E.E.G. tracing showed that the background rhythm was irregular and somewhat slow, 6-7/sec. Bursts of high-voltage, $2 \cdot 5-4 / \mathrm{sec}$. slow waves appeared at intervals of two to 10 seconds. Sometimes the bursts of slow waves were interspersed with rudimentary spikes. 0 There were no clinical signs accompanying the bursts The patient did not cooperate for hyperventilation. Photic stimulation failed to give further information (Fig. 1).

Pneumoencephalography showed increased collection: of air above the convexity, more pronounced above the frontal lobes. The ventricles were somewhat enlarged. $\overline{0}$ Fundoscopic examination showed pallor of the optic $\frac{\bar{O}}{\circ}$ discs. Blood vessels showed no changes and appeared to $\overline{\bar{\omega}}$ be normal. The patient was in hospital for three months, $\stackrel{\vec{\Phi}}{\vec{D}}$ during which period slight improvement of her condition was noted, with a decrease in spasticity. At the end she was able to walk. The laboratory findings concerning her $\overrightarrow{\vec{O}}$ uraemic state and the phenylketonuria also improved to $a$ ? certain degree. The patient was discharged from hospital $\overrightarrow{\vec{\omega}}$ but was readmitted one month later in uraemic coma. Her blood urea was $224 \mathrm{mg} . / 100 \mathrm{ml}$. The increase in urea was accompanied by an increase in phenylalanine $\frac{2}{0}$ values: $17.5 \mathrm{mg} . / 100 \mathrm{ml}$. in the blood, $9.3 \mathrm{mg} . / 100 \mathrm{ml}$. in cerebrospinal fluid, and $100 \mathrm{mg} . / 24 \mathrm{hr}$. in the urine. Her condition gradually deteriorated and she died two mont $\mathrm{B}$ ? later.

\section{NECROPSY FINDINGS}

The body was that of a well-nourished young woma․을 The skin and hair were fair. Oedema of the lowe. extremities was noted and severe atrophy of the lig muscles was observed. The lungs showed sevefe oedema and focal bronchopneumonia. The heart weighed $240 \mathrm{~g}$. Multiple small scars were scattered in the myocardium of both ventricles; they measured $2-5 \mathrm{~cm}$. in diameter and were composed of young connective tissue (Fig. 2). Several lymphocytes,

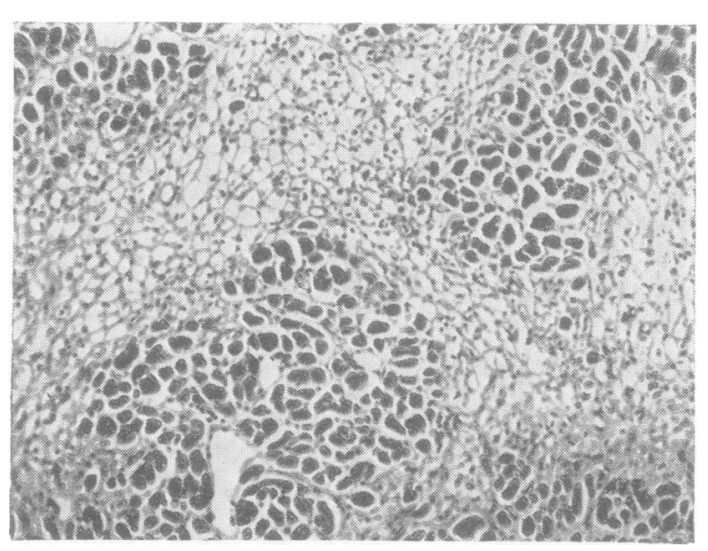

FIG. 2. Myocardium, left ventricle, showing extensive necrosis. Haematoxylin and eosin $\times 60$. 
monocytes, and haemosiderin-containing macrophages were dispersed within the scars. Only a few collagen fibres were observed within the scars, mostly composed of thin reticular fibres. The endocardium was smooth. On the upper surface of the mitral leaflets, small, pin-pointed vegetations, rough and yellowish, were seen. These vegetations were composed of fibrin; no inflammatory cells were observed within or in the vicinity of the vegetations. No bacteria were identified. These vegetations were defined as non-bacterial thrombotic endocarditis (marantic or terminal endocarditis).

The liver weighed $1,050 \mathrm{~g}$. It was brown and the lobular structure was normally preserved. Microscopic examination revealed normal liver cells. No inflammatory or fibrotic changes were observed.

The kidneys were small and shrunken, the right weighing $30 \mathrm{~g}$. and the left $50 \mathrm{~g}$. Their surface was finely granulated and their consistency hard and fibrotic. The cut surface showed a very thin cortex. No sharp margin was seen between the cortex and

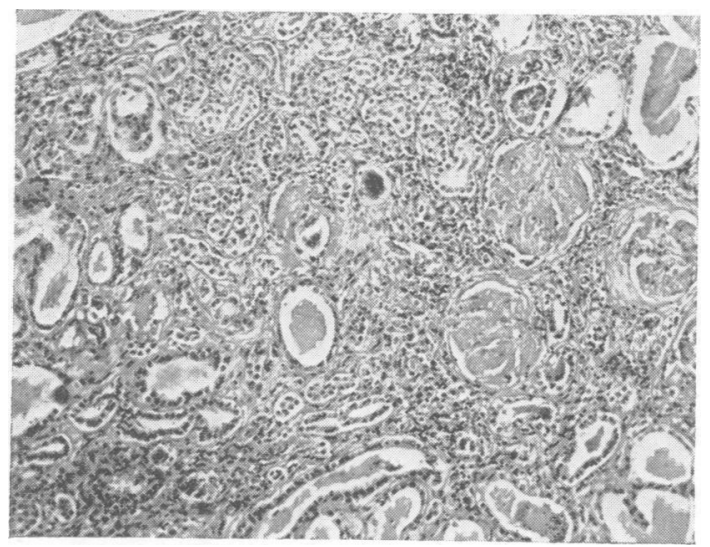

FIG. 3.

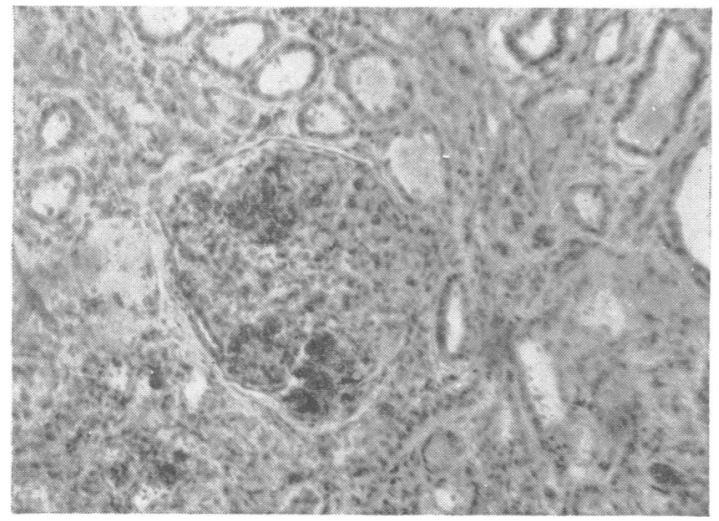

FIG. 4. the medulla of the kidneys. The calyces and ureters showed no lesions. Microscopic examination showed severe changes in the glomeruli, and complete hyalinization of most of the glomeruli. Other glomeruli showed severe periglomerular capsular fibrosis with intense thickening of the basal membrane of the capillar loops (Fig. 3). This thickened basal membrane was positive with periodic-acid Schiff (P.A.S.) stain. Some glomeruli showed increased cellularity, with several foam cells containing sudanophilic material within their cytoplasm (Fig. 4). The tubules were dilated, their epithelial lining atrophic. Interstitital foci of chronic inflammation were present.

The other organs showed no significant pathological changes.

The psoas, gastrocnemius, and diaphragm were examined. Muscle fibres showed vacuolation and homogenization of the cytoplasm (Fig. 5).

The brain weighed $930 \mathrm{~g}$. The leptomeninges were thin and transparent. The arteries of the circle of

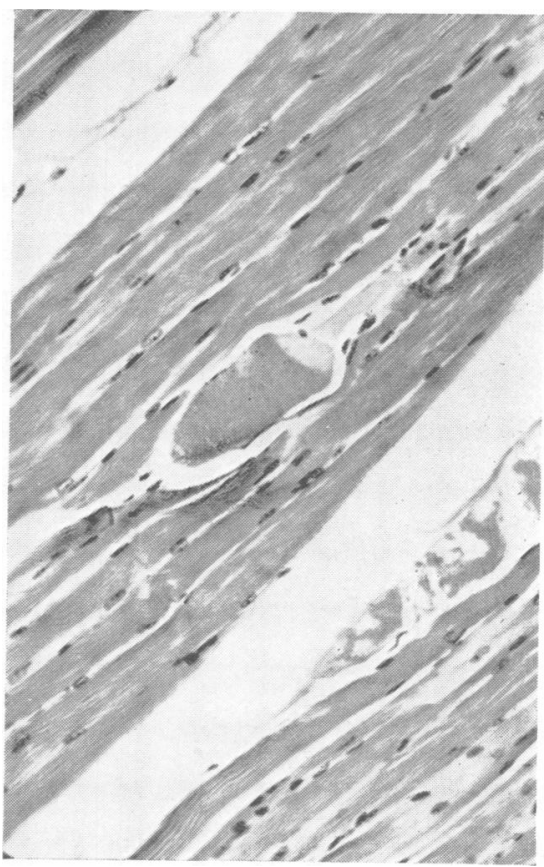

FIG. 5.

FIG. 3. Kidney showing hyalinosis of glomeruli and periglomerular fibrosis $\times 60$.

Fig. 4. Hypercellularity of glomeruli with foam cells containing sudanophilic material. Sudan IV stain $\times 120$.

FIG. 5. Striated muscle from the psoas, showing vacuolation and necrosis of muscle fibres. Haematoxylin and eosin $\times 120$. 


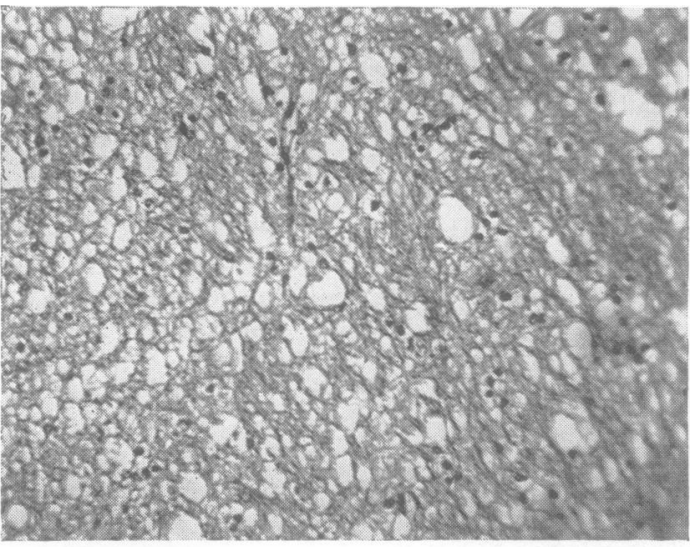

FIG. 6.

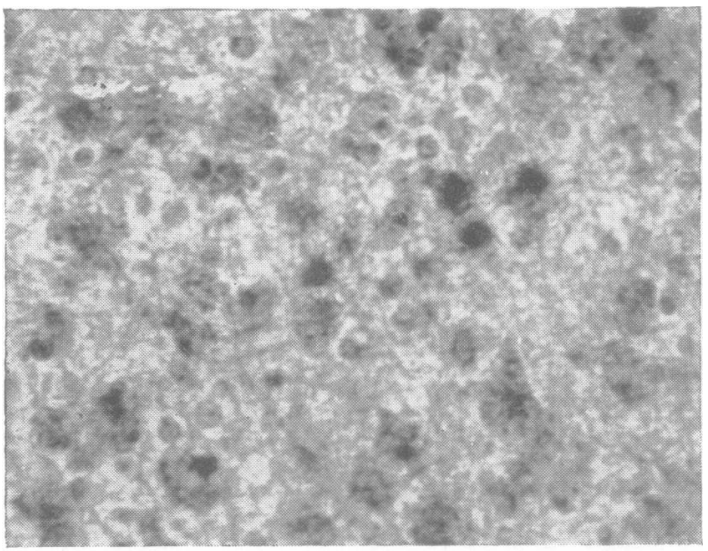

FIG. 8.

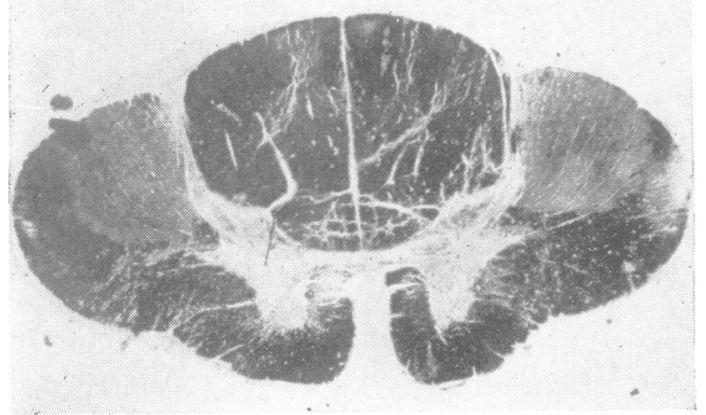

FIG. 10.

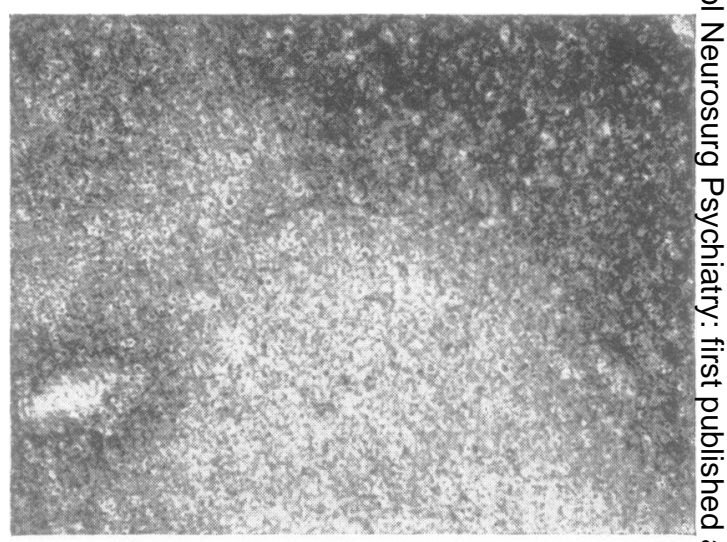

FIG. 7.

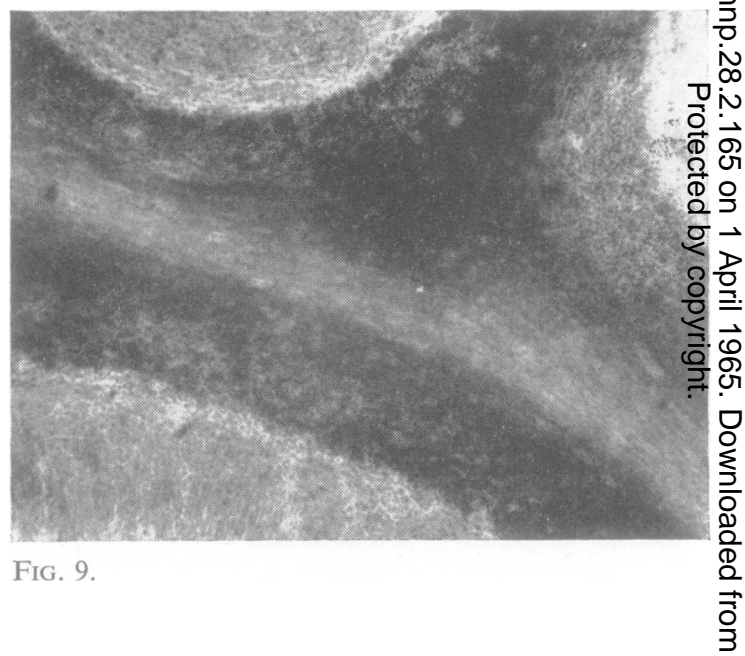

Fig. 6. Spongy state of centrum semiovale. Haematoxylin and eosin $\times 25$.

FIG. 7. Focus of recent demyelination. Spielmeyer $\times 25 \frac{\overline{0}}{0}$

FIG. 8. Sudanophilic droplets in recent demyelination

Fig. 9. Demyelination of cerebellar folia. Spielmeyer $\times 25$.

FIG. 10. Bilateral demyelination of cortico-spinal tracts. Luxol-Fast-Blue $\times 40$. 
Willis showed no changes. The brain was symmetrical. The gyri were somewhat flattened and obstructed the sulci. The cortical ribbon seemed to be narrow, although its colour was grey as usual, and sharp demarcation with the underlying white matter was seen. The ventricles were of normal shape and volume and their ependymal lining was smooth. The basal ganglia, brain-stem, cerebellum, pons, medulla, and spinal cord showed no gross lesions.

MICROSCOPIC EXAMINATION Multiple sections taken from different parts of the cortex showed preservation of the normal architectonic structure of the cortex. The neurones were of normal appearance. Sections taken from the centrum ovale showed that in the vicinity of F1 and F2 and the corpus callosum the white matter was spongy (Fig. 6), the spongy regions showing slight gliosis composed mostly of fibrillary astrocytes. Myelin stain (frozen sections-Spielmeyer) showed that the myelin sheaths had disappeared from these regions. No sudanophilic breakdown material was observed nor were compound granular cells seen. With toluidine blue and the P.A.S. stain, neither metachromatic nor P.A.S.-positive material was identified. Bielschowsky silver impregnation revealed severe loss of the neurofibrils in the spongy regions. Sections of the centrum ovale of the parietal and temporal lobes showed well-demarcated foci measuring 5-6 mm. in diameter in which myelin, though present, was very pale with the above mentioned stain. Identical findings were observed with the Luxol-fast blue stain. Bielschowski stain revealed normal axons traversing these pale regions but no spongy state or gliosis was observed there (Fig. 7). Multiple small foci were scattered in the white matter, and myelin stain disclosed the disappearance of the myelin sheath while Sudan stain revealed an abundance of sudanophilic droplets lying within macrophages or free in the tissue (Fig. 8). In these foci, neither metachromatic nor P.A.S.-positive material was found. Many compound granular cells were seen in the foci. Several small blood vessels in the centrum ovale and basal ganglia showed calcification of their walls in the form of small drops. No other vascular changes were noted. The lumina of the vessels were present in the calcified vessels also. In spite of a very careful search for small emboli in the lumina of the blood vessels none were observed.

Symmetrical demyelination of the cortico-spinal tracts was seen and an abundance of sudanophilic droplets in the demyelinating zones (Fig. 10). Minimal gliosis was noted in these regions. The neurones of the anterior and posterior horns were of normal appearance.

The cerebellum showed linear demyelination of the folia (Fig. 9). No myelin breakdown materials were found.

Peripheral nerves showed no pathological changes.

The blood vessels showed no lesion. No atherosclerotic or hypertensive changes were detected.

\section{DISCUSSION}

The brain lesions and the neurological and mental symptoms of phenylketonuria are known to appear during the first years of life. After the disease has once been established, there is no progression of symptoms. According to Grüter (1963), the most vulnerable period is that up to the age of 2 years, but the noxious agent continues to be active until puberty, although it seems to be less harmful as from this age on the disease process is stationary. In our patient, the disease also seemed to be static up till the age of 22. At this time a sudden deterioration took place in her mental and neurological state, as noted by the psychological tests and by the quadriplegia.

The pathological findings corresponded to the clinical behaviour. Two different types of lesions were found in the central nervous system. The spongy regions of the white matter and the demyelination of different zones can be considered as the early lesions of phenylketonuria. The foci of demyelination with abundant sudanophilic material found dispersed in the centrum ovale and the bilateral degeneration of the cortico-spinal tracts must be considered to be the more recent lesions which cannot be attributed to the primary attack of phenylketonuria between birth and the age of 2 years. The aggravation in the clinical course of the disease occurred simultaneously with uraemia. As the blood urea rose, the phenylketones rose in the blood and cerebrospinal fluid, and the patient's condition deteriorated. It can thus be speculated that the progressive renal failure was responsible for the progressive elevation of phenylalanine and its metabolites, thus causing the recent lesions in the central nervous system.

The presence of quadriplegia with striking bilateral degeneration of the pyramidal tracts is a rare phenomenon in this disease. It is generally accepted that degeneration of the posterior columns of the spinal cord may be caused by metabolic disorders. The development of paraplegia has been described in cases of cirrhosis and following porto-caval shunt operations (Summerskill, Davidson, Sherlock, and Steiner, 1956; Scobie and Summerskill, 1964). It is thus most interesting to see the development of pyramidal tract lesions in other defects of aminoacid metabolism.

The pathological findings consisting of status spongiosus and regions of pallor of myelin were 
described by Poser and Van Bogaert (1959) in an 18-year-old boy who suffered from phenylketonuria. These authors regard the above-mentioned pathological findings as the end result of the process or what might be called the static stage of the disease. Alvord, Stevenson, Vogel, and Engle (1950), on examining the brains of two young children and three adults, assumed that the lack of myelin is due to retarded myelination and demyelination of already existing myelin, and suggested that the cause was a defect in myelin anabolism. The same conclusions were reported by Benda (1952). This author examined two adult cases of phenylketonuria and found severe demyelination with spongy degeneration accompanied by accumulation of metachromatic material. The report of a case somewhat similar to ours was published by Jervis (1954). He described a 25-year-old man with lesions typical of Schilder's disease. According to this author the 'Schilder type' lesions represented a coincidental occurrence of two diseases, namely, phenylketonuria and Schilder's disease. The widespread diffuse necrosis of the myocardium and the focal degeneration of striated muscle are difficult to explain. Myocardial lesions were observed in uraemia, but never to such an extent as in this case. During the patient's period in hospital the renal disease was considered to be a chronic progressive pyelonephritis. Necropsy revealed some outstanding features. The presence of neutral fatcontaining cells within the glomeruli and the P.A.S. positive thickening of the basal membrane of capillary loops is not a regular finding in chronic pyelonephritis. Similar changes were described by Whalen, Huang, Peschel, and McIntosh (1961) in hereditary nephropathies. Whether or not the prolonged secretion of phenylanaline by the kidney was a responsible factor in the development of the renal disease is an open question. It seems to us that the accumulation of phenylanaline at the later stages of the disease was responsible for the recent lesions in the central nervous system, as well as for the myocardial and muscular lesions. We assume that the renal damage was at least partially mediated by the toxic effect of phenylanaline and its metabolites.

\section{SUMMARY}

A 23-year-old woman died of uraemia. She had been mentally retarded since childhood. The exacerbation of the uraemia was accompanied by a severe deterioration in her mental state and in the neurological symptoms. The increase in phenylalanine values corresponded to that of the urea. Examination at necropsy revealed two types of lesions: a spongy state of the white matter, and recent foci of demyelination with bilateral demyelination of the pyramidal tracts. Recent myocardial and striated muscle necrosis was observed and was attributed to the increase in phenylanaline values. It is assumed that the renal lesions were also influenced by the toxic effect of phenylanaline and its metabolites. The relation between the symptoms and the postmortem findings is discussed.

\section{REFERENCES}

Alvord, E. C., Stevenson, L. D., Vogel, F. S., and Engle, R. L. (1950). Neuropathological findings in phenyl-pyruvic oligophrenia (phenylketonuria). J. Neuropath. exp. Neurol., 9, 298-310. Benda, C. E. (1952). Developmental Disorders of Mentation and $\mathrm{N}^{\infty}$
Cerebral Palsies. Grune and Stratton, New York.

Caudle, H. V. (1960). Phenylketonuria without mental retardation Pediatrics, 26, 502.

Grüter, W. (1963). Angeborne Stoffwechselstörungen und Schwachsin am Beispiel der Phenylketonurie. Enke, Stuttgart.

Guthrie, R., and Susi, A. (1963). A simple phenylalanine method fo̊ detecting phenylketonuria in large populations of newbor infants. Pediatrics, 32, 338-343.

Hudson, F. P., Dickinson, R. A., and Ireland, J. T. (1963). Exper $8 \frac{7}{2}$ ences in the detection and treatment of phenylketonurive Ibid., 31, 47-57.

Jervis, G. A. (1954). Phenylpyruvic oligophrenia (phenylketonuria Res. Publ. Ass. nerv. ment. Dis., 33, 259-282.

Poser, C. M.., and Van Bogaert, L. (1959). Neuropathologic observations in phenylketonuria. Brain, 82, 1-9.

Scobie, B. A., and Summerskill, W. H. J. (1964). Permanent paraplegia with cirrhosis. Arch. intern. Med., 113, 805-810.

Summerskill, W. H. J., Davidson, E. A., Sherlock, S., and Steiner, $\bar{O}$ R. E. (1956). The neuropsychiatric syndrome associated with hepatic cirrhosis and an extensive portal collateral circulation. Quart. J. Med., 25, 245-266.

Sutherland, B. S., Berry, H. K., and Shirkey, H. C. (1960). A syndrome of phenylketonuria with normal intelligence and behavior disturbances. J. Pediat., 57, 521-525.

Whalen, R. E., Huang, S., Peschel, E., and McIntosh, H. D. (1961). Hereditary nephropathy, deafness and renal foam cells. Amer. J. Med., 31, 171-186.

Woolf, L. I., Ounsted, C., Lee, D., Humphrey, M., Cheshire, N. M., and Steed, G. R. (1961). Atypical phenylketonuria in sisters with normal offspring. Lancet, 2, 464-465. 